\title{
Peningkatan Literasi Saintifik melalui Pembelajaran Biologi Menggunakan Pendekatan Saintifik
}

\author{
Adib Rifqi Setiawan \\ *) Madrasah Tasywiquth Thullab Salafiyyah (TBS) Kudus, Indonesia \\ email: alobatnic@gmail.com
}

\begin{abstract}
ABSTRAK
Pembelajaran yang bertujuan untuk meningkatkan kemampuan siswa secara optimal harus dilakukan melalui langkah terstruktur dan terukur. Salah satu cara untuk menyusun pembelajaran yang sesuai dengan prinsip tersebut ialah menggunakan pendekatan saintifik. Tujuan dari penelitian ini ialah untuk mendapatkan peningkatan kompetensi literasi saintifik siswa setelah diterapkan pendekatan saintifik dalam pembelajaran biologi topik plantae dan animalia di sekolah menengah. Metode penelitian yang dipilih ialah quasi-experimental dengan desain time series. Sampel sebanyak 120 siswa dari sekolah menengah di Kabupaten Kudus diambil menggunakan teknik convenience sampling. Desain penelitian berupa 16 kali pengamatan, yakni 8 kali sebelum diberikan tindakan berupa hasil pretest dan 8 kali setelah diberikan tindakan berupa hasil posttest serta tindakan berupa penerapan pendekatan saintifik ke dalam pembelajaran. Instrumen yang dipakai berupa tes tipe uraian topik plantae dan animalia yang disusun berdasarkan indikator kompetensi literasi saintifik PISA. Hasil yang diperoleh ialah peningkatan kompetensi literasi di kategori sedang dengan nilai sebesar 0,663. Melalui penelitian ini terungkap bahwa pembelajaran menggunakan pendekatan saintifik memungkinkan untuk dipakai melatih literasi saintifik siswa.
\end{abstract}

Kata-kata kunci: Literasi Saintifik, Pembelajaran Biologi, Pendekatan Saintifik

\begin{abstract}
Learning that aims to improve students' abilities optimally must be done through structured and measurable steps. One way to arrange learning in accordance with these principles is to use a scientific approach. The purpose of this study was to obtain an increase in students' scientific literacy competencies after applying the scientific approach in learning biology on plantae and animalia topics in secondary schools. The research method chosen was quasi-experimental with time series design. A sample of 120 students from secondary schools in Kudus Regency was taken using convenience sampling techniques. The research design took the form of 16 observations, namely 8 times before being given the action as a result of the pretest and 8 times after being given the action in the form of posttest results and actions in the form of applying the scientific approach to learning. The instrument used was essay test of plantae and animalia which was constructed based on PISA scientific literacy competency indicators. The results
\end{abstract}


obtained were an increase in literacy competencies in the medium category with a value of 0.663. Through this research, it was revealed that learning using a scientific approach made it possible to use students to train scientific literacy.

Keywords: Biology Learning, Scientific Approach, Scientific Literacy

\section{PENDAHULUAN}

Pembelajaran yang bertujuan untuk meningkatkan kemampuan siswa secara optimal harus dilakukan melalui langkah terstruktur dan terukur. Struktur pembelajaran yang baik diterapkan secara bertahap mulai dari langkah sederhana sampai rumit. Seluruh langkah tersebut dibuat agar dapat diukur, baik dari sisi pelaksanaan maupun pencapaian. Hal ini berlaku secara umum, termasuk dalam pembelajaran Ilmu Pengetahuan Alam (IPA) seperti biologi, fisika, kimia, geologi, dan astronomi. Salah satu cara untuk menyusun pembelajaran yang sesuai dengan prinsip tersebut ialah menggunakan pendekatan saintifik (Setiawan, 2019, hlm. 8). Nurohmah (2015) menjelaskan melalui one-group pretest-posttest menemukan bahwa pendekatan saintifik mempunyai efektivitas tinggi dalam meningkatkan hasil belajar tiap aspek kognitif siswa pada jenjang pengetahuan, pemahaman, dan penerapan. Secara umum pendekatan saintifik tersusun atas beberapa langkah kegiatan berurutan, ialah: mengamati, menanya, mengumpulkan informasi, melakukan percobaan, mengolah data, serta mengomunikasikan hasil (Setiawan, 2019: 2). Langkah tersebut dipakai guna memberi pengalaman kepada siswa agar informasi yang diperoleh lebih bermakna, teruji, dan dapat dipertanggungjawabkan.

Pembelajaran menggunakan pendekatan saintifik memungkinkan untuk dipakai melatih literasi saintifik siswa. Hal ini seperti ditunjukkan oleh Setiawan (2017) melalui one-group pretest-posttest dalam pembelajaran fisika topik mekanika memperoleh hasil bahwa pendekatan saintifik dapat meningkatkan literasi saintifik siswa pada kategori sedang dengan nilai peningkatan sebesar 0,61. Lebih lanjut, informasi tersebut disertai dengan saran agar dilakukan penerapan pada topik selain mekanika agar mampu melatih literasi saintifik melalui seluruh topik pelajaran, sehingga hasil pembelajaran kian optimal. Berdasarkan tuturan tersebut, kami menerapkan pendekatan saintifik dalam pembelajaran biologi topik plantae dan animalia untuk melatih literasi saintifik siswa. Kompetensi literasi saintifik diukur berdasarkan indikator dari Programme for International Student Assessment (PISA): menjelaskan fenomena secara ilmiah, 
merancang dan mengevaluasi penyelidikan ilmiah, serta menafsirkan data dan bukti secara ilmiah (OECD, 2013, hlm. 15-7). Karena itu rumusan masalahnya ialah, "Bagaimana peningkatan kompetensi literasi saintifik setelah penerapan pendekatan saintifik dalam pembelajaran biologi topik plantae dan animalia di sekolah menengah?” Hasil yang diperoleh diharapkan memberi informasi tentang manfaat penerapan pendekatan saintifik dalam pembelajaran berorientasi literasi saintifik.

\section{METODE PENELITIAN}

Tujuan penelitian ini ialah untuk melihat peningkatan kompetensi literasi saintifik siswa setelah diterapkan pendekatan saintifik dalam pembelajaran biologi topik plantae dan animalia di sekolah menengah di Kabupaten Kudus. Hal itu diperlukan untuk data literasi saintifik sebelum dan setelah pembelajaran Bryophyta, Pteridophyta, Gymnospermae, Angiospermae, Annelida, Arthropoda, Pisces, dan Tetrapoda.

Berdasarkan tujuan penelitian dan kebutuhan data, metode penelitian yang dipilih ialah quasi-experimental dengan desain time series. Dengan metode ini tidak diperlukan kelompok kontrol untuk dibandingkan dengan kelompok eksperimen, tidak menggunakan penyamaan karakteristik dalam satu kelompok tindakan, dan tidak memerlukan pengontrol variabel (Fraenkel \& Wallen, 2009, hlm. 271). Untuk desain time series, kelompok yang digunakan untuk penelitian tidak dapat dipilih secara random sampling, sehingga sampel diambil menggunakan teknik convenience sampling (Fraenkel \& Wallen, 2009, hlm. 101). Partisipan penelitian ini ialah siswa sekolah menengah. Populasi dalam penelitian ini adalah siswa sekolah menengah di Kabupaten Kudus yang diambil 120 siswa sebagai sampel.

Desain penelitian berupa 16 kali pengamatan, yakni 8 kali sebelum diberikan tindakan berupa hasil pretest $\left(\mathrm{O}_{1}, \mathrm{O}_{2}, \mathrm{O}_{3}, \mathrm{O}_{4}, \mathrm{O}_{5}, \mathrm{O}_{6}, \mathrm{O}_{7}, \mathrm{O}_{8}\right)$ dan 8 kali setelah diberikan tindakan berupa hasil posttest $\left(\mathrm{O}_{9}, \mathrm{O}_{10}, \mathrm{O}_{11}, \mathrm{O}_{12}, \mathrm{O}_{13}, \mathrm{O}_{14}, \mathrm{O}_{15}, \mathrm{O}_{16}\right)$ serta tindakan berupa penerapan pendekatan saintifik ke dalam pembelajaran biologi topik plantae meliputi Bryophyta, Pteridophyta, Gymnospermae, dan Angiospermae serta Animalia mencakup Annelida, Arthropoda, Pisces, dan Tetrapoda yang dilaksanakan secara malar (P). Desain tersebut ditunjukkan dengan pola di bawah ini (Fraenkel \& Wallen, 2009, hlm. 272). 


$\begin{array}{lll}\mathrm{O}_{1} & & \mathrm{O}_{9} \\ \mathrm{O}_{2} & & \mathrm{O}_{10} \\ \mathrm{O}_{3} & & \mathrm{O}_{11} \\ \mathrm{O}_{4} \\ \mathrm{O}_{5} \\ \mathrm{O}_{6} \\ \mathrm{O}_{7} \\ \mathrm{O}_{8}\end{array} \quad \Rightarrow \mathrm{P} \Rightarrow \begin{aligned} & \mathrm{O}_{12} \\ & \mathrm{O}_{13} \\ & \mathrm{O}_{14} \\ & \mathrm{O}_{15} \\ & \end{aligned}$

Instrumen yang dipakai berupa tes tipe uraian terkait topik Bryophyta (T1), Pteridophyta (T2), Gymnospermae (T3), Angiospermae (T4), Annelida (H1), Arthropoda $(\mathrm{H} 2)$, Pisces (H3), dan Tetrapoda (H4) yang disusun berdasarkan indikator kompetensi literasi saintifik PISA.

Tabel 1. Sebaran Topik Instrumen Penelitian

\begin{tabular}{cll}
\hline \multicolumn{1}{c}{ Topik } & \multicolumn{1}{c}{ Rincian } & \multicolumn{1}{c}{ Penggunaan } \\
\hline Plantae (T) & Bryophyta (T1) & $\mathrm{O}_{1}$ dan $\mathrm{O}_{9}$ \\
& Pteridophyta (T2) & $\mathrm{O}_{2}$ dan $\mathrm{O}_{10}$ \\
& Gymnospermae (T3) & $\mathrm{O}_{3}$ dan $\mathrm{O}_{11}$ \\
& Angiospermae (T4) & $\mathrm{O}_{4}$ dan $\mathrm{O}_{12}$ \\
Animalia (H) & Annelida (H1) & $\mathrm{O}_{5}$ dan $\mathrm{O}_{13}$ \\
& Arthropoda (H2) & $\mathrm{O}_{6}$ dan $\mathrm{O}_{14}$ \\
& Pisces (H3) & $\mathrm{O}_{7}$ dan $\mathrm{O}_{15}$ \\
& Tetrapoda (H4) & $\mathrm{O}_{8}$ dan $\mathrm{O}_{16}$ \\
\hline
\end{tabular}

Tabel 2. Indikator Domain Kompetensi Literasi Saintifik

\begin{tabular}{ll}
\hline Domain kompetensi & Indikator literasi saintifik \\
\hline Menjelaskan fenomena secara & Mengingat dan menerapkan pengetahuan ilmiah \\
ilmiah (L1) & yang sesuai \\
& $\begin{array}{l}\text { Mengidentifikasi, menggunakan, serta } \\
\text { menghasilkan model dan representasi yang jelas } \\
\text { Menjelaskan implikasi potensial dari pengetahuan } \\
\text { ilmiah bagi masyarakat }\end{array}$ \\
& Mengusulkan cara mengeksplorasi secara ilmiah \\
Merancang dan mengevaluasi & terhadap pertanyaan yang diberikan \\
penyelidikan ilmiah (L2) & $\begin{array}{l}\text { Mengevaluasi cara mengeksplorasi secara ilmiah } \\
\text { pertanyaan yang diberikan } \\
\text { Mendeskripsikan dan mengevaluasi berbagai cara } \\
\text { yang digunakan oleh ilmuan untuk menentukan }\end{array}$
\end{tabular}


keabsahan dan keobjektifan data serta keumuman penjelasan

Menafsirkan data dan bukti secara ilmiah (L3)
Mengubah data dari satu representasi ke representasi yang lain

Menganalisis dan menafsirkan data dan menarik kesimpulan yang tepat

Contoh instrumen terkait tetrapoda (H4) dengan indikator menafsirkan data dan bukti secara ilmiah (L3) yaitu, "Metabolisme adalah seluruh reaksi kimia di dalam sel organisme yang berjalan satu arah. Salah satu metabolisme yang terjadi di tubuh Rosé ialah pembakaran glukosa $\left(\mathrm{C}_{6} \mathrm{H}_{12} \mathrm{O}_{6}\right)$ menjadi karbondioksida $\left(\mathrm{CO}_{2}\right)$ dan air $\left(\mathrm{H}_{2} \mathrm{O}\right)$. Berdasarkan metabolisme yang dialami, apa manfaat Rosé bagi ekosistem?" yang dijawab dengan, "Menghasilkan karbondioksida yang dibutuhkan oleh organisme lain seperti tumbuhan dan bakteri sehingga menjaga aliran energi di Bumi."

Keabsahan (validity) instrumen ditentukan berdasarkan validasi ahli (obtain judgement expert), masing-masing terhadap kesesuaian indikator dengan soal, kesesuaian jawaban dengan pertanyaan, serta kesesuaian soal dengan jenjang sekolah (Fraenkel \& Wallen, 2009, hlm. 148). Hasil validasi berupa penilaian terhadap setiap butir soal yang diolah menggunakan persamaan berikut:

$$
\begin{aligned}
& P(b s)=\frac{b s}{N} \times 100 \% \quad \text { (Persamaan 1. Penilaian Butir) } \\
& \text { dengan: } \\
& P(b s)=\text { persentase setiap butir soal } \\
& b s \quad=\text { jumlah skor setiap butir soal } \\
& N \quad=\text { jumlah keseluruhan butir soal }
\end{aligned}
$$

kemudian ditafsirkan berdasarkan tabel berikut:

Tabel 3. Penafsiran penilaian instrumen

\begin{tabular}{ccc}
\hline No. & Rentang rata-rata penilaian ahli $(\%)$ & Kriteria instrumen \\
\hline 1 & $7,001 \leq \% \leq 10,000$ & Sangat layak \\
2 & $4,001 \leq \% \leq 7,000$ & Cukup layak \\
3 & $0,000 \leq \% \leq 4,000$ & Tidak layak
\end{tabular}

Berdasarkan Tabel 3, instrumen dapat digunakan kalau memenuhi kriteria 'sangat layak' atau 'cukup layak'. 
Sementara keandalan (reliability) instrumen ditentukan berdasarkan internal consistency karena bisa dilakukan dengan satu kali uji coba. Maka instrumen dapat digunakan kalau nilai koefisien keandalan (reliability coefficient) lebih besar dari 0,70 (Fraenkel \& Wallen, 2009, hlm. 157-8). Koefisien keandalan dapat dihitung menggunakan persamaan Kuder-Richardson Approaches (KR20) berikut (Cronbach, 1951, hlm. 299):

$$
\begin{aligned}
\alpha=\frac{n}{n-1}(1 & \left.-\frac{\sum_{i} V_{i}}{V_{t}}\right) \quad \text { (Persamaan 2. KR20) } \\
\text { dengan: } & \\
\alpha \quad & \text { koefisien alfa } \\
n \quad & =\text { jumlah butir soal } \\
V i \quad & =\text { simpangan baku setiap butir soal } \\
V t \quad & =\text { simpangan baku keseluruhan }
\end{aligned}
$$

Setelah dilakukan validasi kepada 3 ahli dan uji coba terhadap 40 siswa ditemukan bahwa instrumen 'sangat layak' sebanyak 42\% dan 58\% 'cukup layak' serta nilai koefisien keabsahan memenuhi kriteria dapat digunakan.

Tabel 4. Hasil Validasi Ahli Setiap Instrumen

\begin{tabular}{llll}
\hline Instrumen & Sangat layak & Cukup layak & Tidak layak \\
\hline T1 & 6 & 2 & 0 \\
T2 & 6 & 2 & 0 \\
T3 & 6 & 2 & 0 \\
T4 & 4 & 4 & 0 \\
H1 & 3 & 5 & 0 \\
H2 & 7 & 0 \\
H3 & 1 & 8 & 0 \\
H4 & 0 & 7 & 0 \\
\hline
\end{tabular}

Tabel 5. Hasil uji coba

\begin{tabular}{lll}
\hline & \multicolumn{1}{c}{ Instrumen } & \multicolumn{1}{c}{ Koefisien alfa } \\
\hline T1 & 0,710 & Dapat digunakan \\
T2 & 0,746 & Dapat digunakan \\
T3 & 0,793 & Dapat digunakan \\
T4 & 0,705 & Dapat digunakan \\
H1 & 0,900 & Dapat digunakan \\
H2 & 0,703 & Dapat digunakan \\
H3 & 0,779 & Dapat digunakan \\
H4 & 0,703 & Dapat digunakan \\
\hline
\end{tabular}


Penyekoran instrumen dilakukan dengan menggunakan persamaan berikut:

$$
\begin{array}{cl}
S=\sum R & \quad \text { (Persamaan 3. Skor Siswa) } \\
\text { dengan: } & \\
S \quad \text { = } & \text { skor setiap siswa } \\
R \quad=\text { jawaban setiap butir soal }
\end{array}
$$

\section{HASIL DAN PEMBAHASAN}

Hasil keseluruhan kompetensi literasi saintifik siswa diperoleh meningkat di kategori sedang dengan nilai peningkatan sebesar 0,663. Hasil yang diperoleh dari pretest tidak stabil, tapi dengan bentuk garis yang memenuhi persamaan $y=-0,0838 x+$ 11,585, dapat dikatakan bahwa ketidakstabilan kurang signifikan karena memiliki rentang perbedaan sebesar 1,257 poin dalam skala 30 poin. Ketidakstabilan yang serupa juga diperoleh dari hasil posttest yang garisnya memenuhi persamaan $y=-0,2534 x+$ 24,809 . Hanya saja rentang perbedaan posttest lebih lebar daripada pretest sebesar 3,801 poin.

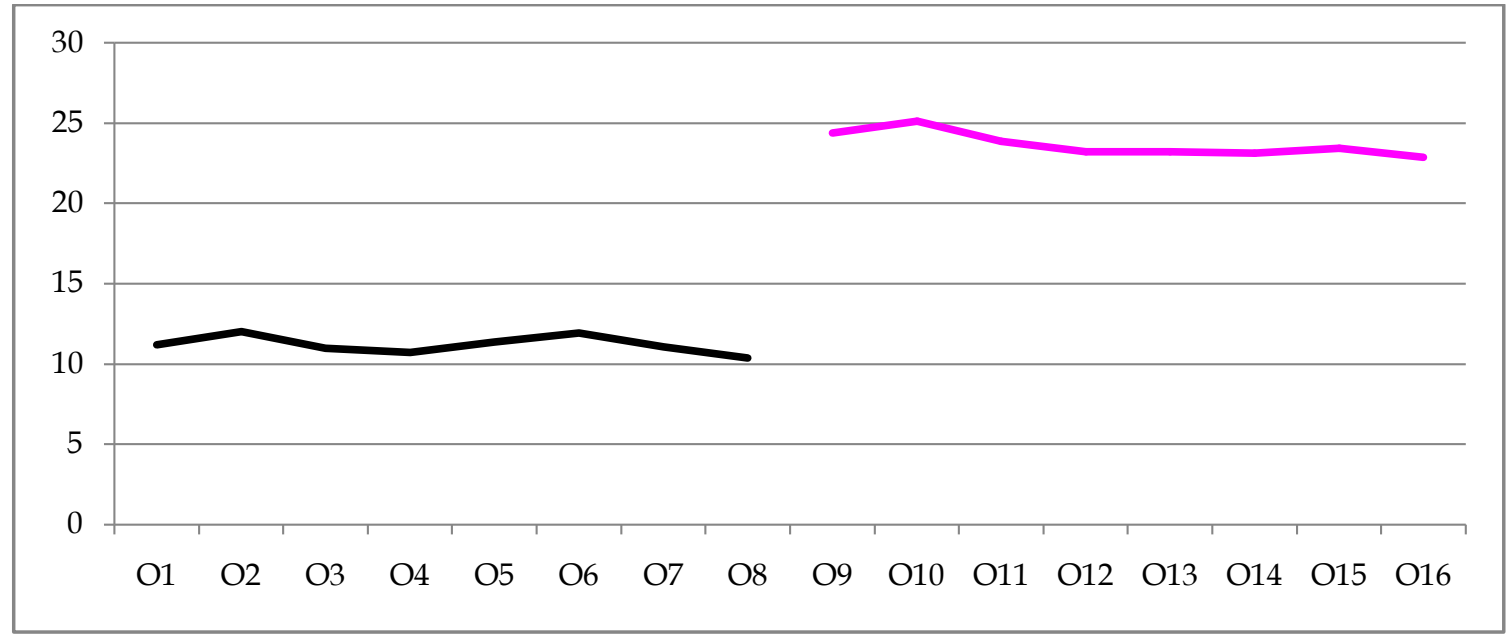

Gambar 1. Kecenderungan data setiap tahap penelitian

Berdasarkan Gambar 1, tampak bahwa dari pretest (black's line) ke posttest (pink's line) terdapat peningkatan. Nilai peningkatan untuk setiap tahap penelitian sebagai berikut:

Tabel 6. Nilai peningkatan untuk setiap tahap penelitian

\begin{tabular}{cccccc}
\hline \multirow{2}{*}{ Tahap penelitian } & \multicolumn{2}{c}{ Rata-rata } & \multicolumn{2}{c}{ Peningkatan } \\
\cline { 3 - 6 } & & Pretest & Posttest & Nilai & Kategori \\
\hline $\mathrm{O}_{1}$ & $\mathrm{O}_{9}$ & 11,213 & 24,393 & 0,702 & Tinggi \\
$\mathrm{O}_{2}$ & $\mathrm{O}_{10}$ & 12,000 & 25,148 & 0,730 & Tinggi \\
$\mathrm{O}_{3}$ & $\mathrm{O}_{11}$ & 10,984 & 23,877 & 0,678 & Sedang
\end{tabular}




$\begin{array}{llllll}\mathrm{O}_{4} & \mathrm{O}_{12} & 10,730 & 23,221 & 0,648 & \text { Sedang } \\ \mathrm{O}_{5} & \mathrm{O}_{13} & 11,352 & 23,246 & 0,638 & \text { Sedang } \\ \mathrm{O}_{6} & \mathrm{O}_{14} & 11,943 & 23,148 & 0,621 & \text { Sedang } \\ \mathrm{O}_{7} & \mathrm{O}_{15} & 11,074 & 23,434 & 0,653 & \text { Sedang } \\ \mathrm{O}_{8} & \mathrm{O}_{16} & 10,369 & 22,885 & 0,638 & \text { Sedang }\end{array}$

Kompetensi merancang dan mengevaluasi penyelidikan ilmiah (L2) mengalami peningkatan paling tinggi, yang secara berurutan diikuti oleh menjelaskan fenomena secara ilmiah (L1) kemudian menafsirkan data dan bukti secara ilmiah (L3).

Tabel 7. Rincian Peningkatan Setiap Kompetensi

\begin{tabular}{clccl}
\hline \multirow{2}{*}{ Kompetensi } & \multicolumn{2}{c}{ Rata-rata } & \multicolumn{2}{c}{ Peningkatan } \\
\cline { 2 - 5 } & Pretest & Posttest & Nilai & \multicolumn{1}{c}{ Kategori } \\
\hline L1 & 29,585 & 63,492 & 0,673 & Sedang \\
L2 & 29,756 & 65,385 & 0,709 & Tinggi \\
L3 & 29,642 & 60,475 & 0,612 & Sedang \\
\hline
\end{tabular}

Untuk kaitan antara semua kompetensi dengan setiap topik, diperoleh peningkatan kategori tinggi paling banyak untuk kompetensi merancang dan mengevaluasi penyelidikan ilmiah di topik bryophyta, pteridophyta, gymnospermae, angiospermae, dan arthropoda. Kategori tinggi juga diperoleh untuk kompetensi menjelaskan fenomena secara ilmiah di topik bryophyta, pteridophyta, dan annelida. Selebihnya kategori peningkatan berada di kategori sedang.

Tabel 8. Rincian Keseluruhan Peningkatan

\begin{tabular}{|c|c|c|c|}
\hline \multirow{2}{*}{ Topik Pembelajaran Biologi } & \multirow{2}{*}{ Kompetensi Literasi Saintifik } & \multicolumn{2}{|c|}{ Peningkatan } \\
\hline & & Nilai & Kategori \\
\hline \multirow[t]{3}{*}{ Bryophyta } & 1 & 0,716 & Tinggi \\
\hline & 2 & 0,747 & Tinggi \\
\hline & 3 & 0,641 & Sedang \\
\hline \multirow[t]{3}{*}{ Pteridophyta } & 1 & 0,736 & Tinggi \\
\hline & 2 & 0,770 & Tinggi \\
\hline & 3 & 0,688 & Sedang \\
\hline \multirow[t]{3}{*}{ Gymnospermae } & 1 & 0,670 & Sedang \\
\hline & 2 & 0,705 & Tinggi \\
\hline & 3 & 0,663 & Sedang \\
\hline Angiospermae & 1 & 0,621 & Sedang \\
\hline
\end{tabular}




\begin{tabular}{cccc} 
& 2 & 0,720 & Tinggi \\
Annelida & 3 & 0,609 & Sedang \\
& 1 & 0,702 & Tinggi \\
\multirow{3}{*}{ Arthropoda } & 2 & 0,601 & Sedang \\
& 3 & 0,616 & Sedang \\
\multirow{2}{*}{ Pisces } & 1 & 0,597 & Sedang \\
& 2 & 0,769 & Tinggi \\
\multirow{3}{*}{ Tetrapoda } & 3 & 0,499 & Sedang \\
& 1 & 0,647 & Sedang \\
& 2 & 0,670 & Sedang \\
& 3 & 0,643 & Sedang \\
& 1 & 0,685 & Sedang \\
& 2 & 0,699 & Sedang \\
& 3 & 0,529 & Sedang
\end{tabular}

Dapat dilihat dari Gambar 1 bahwa kompetensi literasi saintifik siswa meningkat setelah dilakukan penerapan pendekatan saintifik dalam pembelajaran biologi. Nilai peningkatan sebesar 0,663 menunjukkan bahwa sebagian besar indikator sudah dapat dicapai oleh siswa. Hasil ini menguatkan Nurohmah (2015) yang melalui one-group pretest-posttest menemukan bahwa pendekatan saintifik mempunyai efektivitas tinggi dalam meningkatkan hasil belajar tiap aspek kognitif siswa pada jenjang pengetahuan, pemahaman, dan penerapan. Penelitian Tindakan Kelas (PTK) yang terdiri dari 4 siklus oleh Wahyuni (2018) memperoleh kesimpulan bahwa penerapan pendekatan saintifik dapat meningkatkan aspek pengetahuan dan keterampilan sains pada pelajaran biologi di sekolah menengah. Namun, penerapan pendekatan saintifik oleh keduanya tanpa dikaitkan dengan literasi saintifik. Perbandingan dengan keduanya menunjukkan bahwa pendekatan saintifik dapat memberikan hasil belajar yang baik.

Peningkatan kompetensi literasi saintifik siswa memiliki nilai beragam di kategori sama dengan urutan dari nilai tertinggi ialah: merancang dan mengevaluasi penyelidikan ilmiah (L2) menjelaskan fenomena secara ilmiah (L1), kemudian menafsirkan data dan bukti secara ilmiah (L3). Hasil ini menunjukkan bahwa siswa lebih cakap untuk merancang dan mengevaluasi penyelidikan ilmiah daripada menjelaskan fenomena serta menafsirkan data dan bukti secara ilmiah. Hasil yang diperoleh memiliki perbedaan menyolok dengan hasil penelitian Setiawan (2017) yang memberikan informasi bahwa peningkatan literasi saintifik untuk topik mekanika (fisika) berada di kategori sedang 
dengan urutan: menafsirkan data dan bukti secara ilmiah (L3), merancang dan mengevaluasi penyelidikan ilmiah (L2), dan menjelaskan fenomena secara ilmiah (L1). Perbandingan hasil keduanya menunjukkan bahwa peningkatan untuk kompetensi menjelaskan fenomena secara ilmiah dan merancang dan mengevaluasi penyelidikan ilmiah untuk topik plantae dan animalia lebih tinggi daripada mekanika, tapi hal ini berlaku sebaliknya untuk kompetensi menjelaskan fenomena serta menafsirkan data dan bukti secara ilmiah. Hasil belajar tersebut tampak bahwa siswa lebih sulit menafsirkan data dan bukti secara ilmiah di topik biologi daripada fisika.

Literasi saintifik tampak tidak terkait maupun identik dengan topik tertentu. Hal ini diperlihatkan oleh temuan yang menunjukkan bahwa siswa memiliki peningkatan kompetensi merancang dan mengevaluasi penyelidikan ilmiah (L2) relatif setara meski berbeda topik. Kompetensi L2 ini, siswa tidak dikaitkan secara langsung dengan objek pengamatan dan/atau percobaan karena lebih menekankan terhadap penggunaan metode ilmiah. Walau begitu, rincian hasil yang diperoleh memperlihatkan bahwa topik berbeda memiliki kecenderungan peningkatan berbeda. Gambar 1 dan Tabel 7 memperlihatkan bahwa kompetensi literasi saintifik mengalami peningkatan di kategori sedang dengan nilai beragam untuk setiap topik. Secara beruntun urutannya ialah: pteridophyta (T2), bryophyta (T1), gymnospermae (T3), pisces (H3), angiospermae (T4), tetrapoda (H4), annelida (H1), dan arthropoda (H2). Urutan tersebut justru berbeda dengan pembelajaran yang dilaksanakan, secara malar yakni bryophyta (T1), pteridophyta (T2), gymnospermae (T3), angiospermae (T4), annelida (H1), arthropoda (H2), pisces (H3), dan tetrapoda (H4). Temuan ini menarik karena wajarnya, kalau kompetensi yang dilatih sama, hasil untuk setiap pertemuan cenderung kian apik. Namun, hasil yang diperoleh tidak demikian, justru terasa berantakan.

Dalam pembelajaran secara umum, siswa diminta untuk mengamati organisme terkait topik yang sedang dipelajari. Misalnya untuk topik annelida, siswa diminta untuk mengamati Cacing tanah (Lumbricus terrestris). Peningkatan seperti itu menunjukkan bahwa kompetensi literasi saintifik siswa cenderung lebih mudah dilatih menggunakan objek yang sederhana untuk topik plantae dan objek berukuran besar yang tidak menggunakan mikroskop untuk topik animalia. Artinya, untuk topik plantae, siswa sudah menunjukkan tanda terampil mikroskop buat melakukan pengamatan. Namun, 
keterampilan tersebut terasa kurang berguna ketika memasuki topik animalia. Pasalnya dalam topik animalia, siswa harus berurusan dengan organisme yang lebih lentur, sehingga lebih menyulitkan mereka untuk memotong setiap bagian organisme buat diamati. Hal ini dikuatkan dengan temuan yang menunjukkan bahwa peningkatan kompetensi literasi saintifik untuk pisces (H3) menggunakan Bandeng (Chanos chanos) dan tetrapoda (H4) menggunakan Mencit (Mus musculus), yang lebih mudah dipotong, lebih baik dibandingkan dengan annelida (H1) menggunakan Cacing tanah (Lumbricus terrestris) dan arthropoda (H2) menggunakan Udang jerbung (Fenneropenaeus merguiensis). Hasil ini justru melemahkan anggapan bahwa literasi saintifik tidak identik dengan topik tertentu. Pasalnya perbedaan tingkat kerumitan antar topik ketika diukur dengan indikator yang sama, hasilnya tampak berbeda. Hubungan antara tingkat kerumitan topik dengan peningkatan kompetensi literasi saintifik berbanding terbalik yang dapat ditunjukkan dengan pola berikut:

$$
\text { kompetensi literasi saintifik } \approx \frac{1}{\text { kerumitan topik }}
$$

Hal itu memberikan makna, semakin rumit topik yang dibahas, peningkatan kompetensi kian rendah. Karena itu dalam menyiapkan pembelajaran, urutan topik pelajaran yang dibahas perlu diperhatikan secara seksama berdasarkan tingkat kerumitannya di mata siswa tanpa perlu terpaku dengan panduan dalam kurikulum yang diberlakukan.

Secara keseluruhan, dapat disampaikan bahwa penerapan pendekatan saintifik dalam pembelajaran biologi topik plantae serta animalia dapat meningkatkan kompetensi literasi saintifik siswa. Pendekatan saintifik dipandang cocok digunakan untuk melatih kompetensi literasi saintifik karena siswa dibiasakan untuk menggunakan metode ilmiah dalam memperoleh informasi. Hasil keseluruhan ini sama seperti Fatimah \& Anggrisia (2019) yang menggunakan model pembelajaran 7E (elicited, engage, explore, explain, elaborate, evaluate, dan extend). Namun, pendekatan saintifik memberi peningkatan kategori tinggi untuk kompetensi merancang dan mengevaluasi penyelidikan ilmiah, sedangkan peningkatan menggunakan model 7E berada di kategori sedang di setiap kompetensi. Peningkatan kategori tinggi untuk kompetensi merancang dan mengevaluasi penyelidikan ilmiah juga diperoleh oleh Dinata (2018) ketika melakukan field trip di topik ekosistem. Lebih lanjut, hasil tersebut juga memberi peningkatan kategori tinggi 
untuk kompetensi menjelaskan fenomena secara ilmiah serta sedang untuk menafsirkan data dan bukti secara ilmiah. Field trip memang memberi hasil lebih baik di topik ekosistem, tapi kami memandang bahwa strategi tersebut tidak cocok diterapkan di topik plantae dan animalia. Perbandingan hasil ini memberi pesan bahwa guru selayaknya mengerti karakteristik topik pelajaran, keterampilan yang hendak dilatih dalam pembelajaran, serta keadaan siswa agar hasil yang diperoleh dapat optimal. Perbandingan terhadap beberapa penelitian tersebut sekaligus menunjukkan bahwa tidak ditemukan perbedaan menyolok dengan beragam model pembelajaran. Dengan demikian, kami belum dapat menentukan model terbaik untuk digunakan dalam pembelajaran IPA termasuk biologi. Sehingga kami menganggap bahwa setiap model dapat digunakan dalam pembelajaran IPA selama tidak mengabaikan kegiatan pengamatan (observation) dan/atau peramalan (eksperiment) yang merupakan karakteristik IPA.

\section{SIMPULAN}

Melalui penelitian menggunakan metode quasi-experimental dengan desain time series, jawaban terhadap rumusan masalah ialah secara keseluruhan kompetensi literasi saintifik siswa meningkat di kategori sedang dengan nilai peningkatan sebesar 0,663 setelah dilakukan penerapan pendekatan saintifik dalam pembelajaran biologi topik plantae dan animalia di sekolah menengah. Hasil ini menunjukkan bahwa pembelajaran menggunakan pendekatan saintifik bisa menjadi sarana untuk melatih kompetensi literasi saintifik siswa.

\section{DAFTAR PUSTAKA}

Cronbach, L J. (1951). Coefficient alpha and the internal structure of tests. Psychometrika, 16: 297-334.

Dinata, A N. (2018). the influence of field trip on high school student's scientific literacy and attitude towards science in ecosystem concept. Assimilation: Indonesian Journal of Biology Education, 1(1): 8-13.

Fatimah, F M \& Anggrisia, N F. (2019). The effectiveness of 7 learning model to improve scientific literacy. Advances in Social Science, Education and Humanities Research, 277: 18-22. 
Fraenkel, J R. \& Wallen, Norman E. (2009). How to Design and Evaluate Research in education (7th ed.). New York. McGraw-Hill Companies.

Nurohmah, E F. (2015). Efektivitas pendekatan saintifik dalam meningkatkan hasil dan motivasi belajar siswa smp. Skripsi. Diterbitkan. Diakses melalui http://bit.ly/2TCEDc9

OECD. (2013). Pisa 2015 draft science framework march 2013. Paris: OECD.

Setiawan, A R. (2019). A Brief Explanation of Scientific Teaching. INA-Rxiv. DOI: https://dx.doi.org/10.31227/osf.io/by9sm

Setiawan, A R. (2017). Penerapan pendekatan saintifik untuk melatihkan literasi saintifik dalam domain kompetensi pada topik gerak lurus di sekolah menengah pertama. Skripsi. Diakses melalui http://bit.ly/2I9NjOn

Wahyuni, S. (2018). Implementasi pendekatan sainstifik pada pelajaran biologi untuk meningkatkan hasil belajar kognitif dan keterampilan sains siswa kelas XI-IPA SMA Negeri 2 Lambandia, Kab. Kolaka Timur- Sultra. Jurnal Pendidikan Biologi, 9(2): 47-55. 